This is an electronic reprint of the original article. This reprint may differ from the original in pagination and typographic detail.

Author(s): Laatikainen, Gabriella; Ojala, Arto; Mazhelis, Oleksiy

Title: $\quad$ Cloud Services Pricing Models

Year: $\quad 2013$

Version:

Please cite the original version:

Laatikainen, G., Ojala, A., \& Mazhelis, O. (2013). Cloud Services Pricing Models. In G. Herzwurm, \& T. Margaria (Eds.), Software Business. From Physical Products to Software Services and Solutions (pp. 117-129). Springer. Lecture Notes in Business Information Processing. https://doi.org/10.1007/978-3-642-39336-5_12

All material supplied via JYX is protected by copyright and other intellectual property rights, and duplication or sale of all or part of any of the repository collections is not permitted, except that material may be duplicated by you for your research use or educational purposes in electronic or print form. You must obtain permission for any other use. Electronic or print copies may not be offered, whether for sale or otherwise to anyone who is not an authorised user. 


\title{
Cloud services pricing models
}

\author{
Gabriella Laatikainen, Arto Ojala and Oleksiy Mazhelis \\ Department of Computer Science and Information Systems \\ University of Jyväskylä \\ Jyväskylä, Finland \\ gabriella.laatikainen@jyu.fi, arto.k.ojala@jyu.fi,mazhelis@jyu.fi
}

\begin{abstract}
A major condition for commercial success is a well-defined pricing strategy, however, cloud service providers face many challenges around pricing. Clearness and transparency in pricing is beneficial for all the actors in the ecosystem, where the currently existing abundance of different pricing models makes decision making difficult for service providers, partners, customers and competitors. In this paper, the SBIFT pricing model is evaluated and updated to cloud context. As a result, a 7-dimensional cloud pricing framework is proposed that helps clarifying the possible pricing models in order to let companies differentiate themselves from competitors by price. The framework can be used also as a tool for price model development and communication about cloud pricing. The taxonomy is based on a broad literature review and empirical research on currently used pricing models of 54 cloud providers.
\end{abstract}

Key words: pricing; revenue logic; cloud; SaaS; PaaS; IaaS

\section{Introduction}

One of the key conditions for commercial success of cloud services is the clearness and transparency of pricing for both customers and providers 1, 2. Properly applied, a well-defined pricing strategy can change customers' behavior and it can determine the offering's position on the competitive market [3. Pricing models influence not only the demand, but have an effect also on the way how users use the product or service, and have a long-term influence on customer relationships [4. Pricing can also differentiate an offering from the competitors [5, 6] and this way increase the company's revenues and position in the market. Therefore pricing is a powerful strategic tool in manager's hands.

However, because of the rapid technology development and increasing competition in the global markets, price modeling for software products became very complex. A number of studies have also suggested that traditional pricing models are not applicable as such for pricing of software products (e.g. 77) and the way of pricing software products is also changing $[\underline{8}$. Hence, there is a constantly changing labyrinth around software pricing with many different pricing solutions [8]. For this reason, cloud solution providers may face many challenges around pricing [9] and pricing of IT services is often a neglected topic for many IT managers [10].

For the above-mentioned reasons, there is a need for a clear and systematic pricing framework, developed especially for cloud industry, that helps decision makers find 
the proper pricing model and evaluate its alternatives, advantages and disadvantages. Hence, the aim of this study is to examine empirically the applicability of an existing pricing model in the context of cloud solutions and, if needed, propose possible modifications to the model. We seek to contribute to the literature of cloud computing by revealing the most popular pricing models used by 54 cloud solution providers. In addition, we propose a model that managers operating in cloud business can use as a tool to evaluate the proper pricing model for their solutions.

\section{Related work}

\subsection{The SBIFT pricing model}

A comprehensive taxonomy of pricing models has been proposed by Iveroth et al. [1], that defines pricing models as systems of price-related characteristics of the agreement between buyer and seller. Price models are described along 5 dimensions, that are listed without priority (see figure 1). According to the authors, price models can be described through the specification of the "positions" on each dimension. The taxonomy is called SBIFT model, that stands for the acronyms of the dimensions.

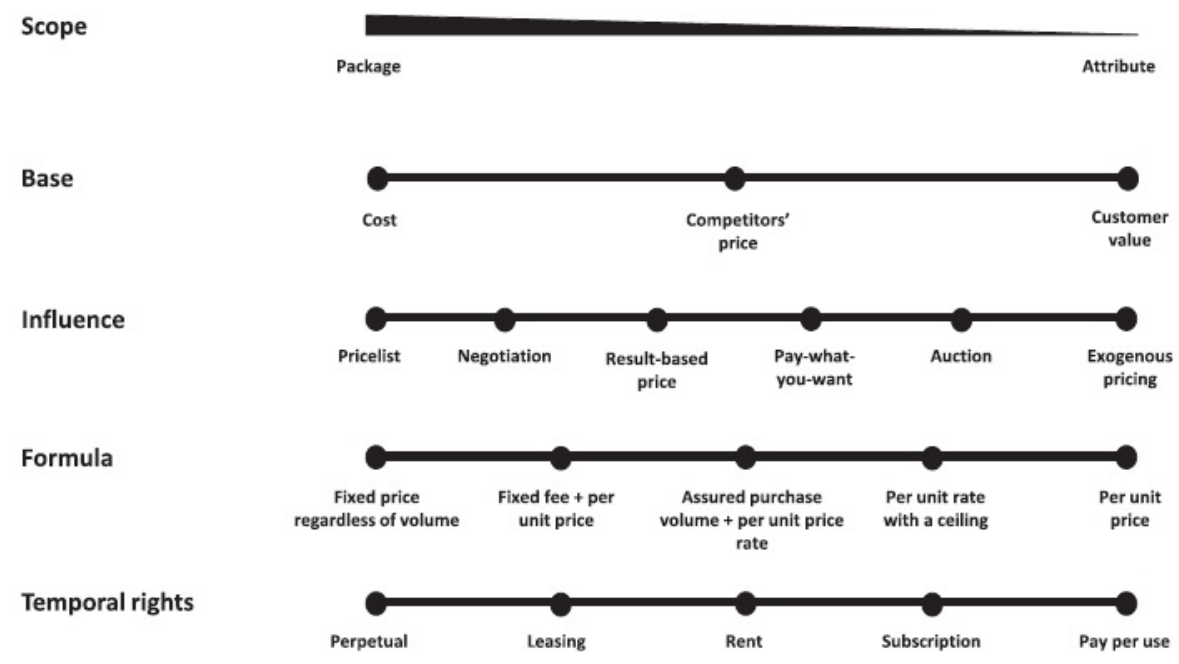

Fig. 1. The SBIFT model 11.

We chose to evaluate this model in cloud context, since it provides the most state-of-the-art and the most integrative work in the current pricing literature. The flexibility of this taxonomy makes it possible to create novel pricing models as a combination of different pricing elements. The model contains pricing elements also from the cloud- and software literature, hence it may be applied to the cloud services easily. The dimensions of the model are presented as follows. 
The Scope dimension refers to the granularity of the offer. At the left side of the slider, a Package of products/services are priced; while the other extreme category is named Attribute, referring to the case when each unit of the offer is priced individually and buyers can decide upon buying them or not.

The Base dimension refers to the information base that dominates the pricing decisions. Cost-based pricing is the most widely used pricing method [12, where the seller determines the price floor based on the cost of developing, producing, distributing and selling the goods. Another pricing formation strategy is setting the price level according to Competitor's price of comparable products or services [13. Using Value-based (demand-based) pricing strategies providers define their prices based on the customers' perceived value [10, 14, 15].

The Influence dimension reflects the ability of buyers and sellers to influence the price. If the price is decided by the provider alone, this is usually communicated through a Pricelist. If the price is set based on a Negotiation between the customer and the provider, then the starting point is also a pricelist but the buyer can influence the final price. The next option is Result-based pricing, where the price is determined based on some observable result of the product/service [11. In an Auction the price is set based on the customers' willingness to pay and the sellers' influence on the price is limited. Exogenous pricing is used if circumstances beyond the sellers' and buyers' influence determine the price.

The Formula dimension refers to the connection between price and volume. With a Fixed price regardless of volume (flat-pricing, eat-all-what-you-can), customers pay a fixed price, that is independent from the used volume [16. The Fixed fee plus per unit rate formula has two components: a fixed, predetermined, volume-independent part and a volume-dependent part. In case of Assured purchase volume plus per unit rate, a fixed amount of volume is priced with a fix price, and an overage price is charged for the extra consumption with the per unit rate. Using the Per unit rate with a ceiling formula, the per unit price has to be paid only until a certain consumption-level, and above that the usage is free of charge [11. In case of Per unit price, units (or units per time) are associated with fixed price values and the customer pays this per unit price regardless of the quality or the economies of scale that the seller might encounter.

The Temporal rights dimension refers to the length of the time period when the user can use the offering. In case of Perpetual offering, the customer can use and own the goods as long as he wants [17, 18, 19. When Leasing, customers buy the right to use the service/product for a fixed period and to buy it after the period on a predefined price. Through Renting the right is bought to use the product or service for a "rental" period, during which the customer does not get any updates or changes to the original product/service. On the other hand, in case of Subscription, buyers have the right to use the service/product for a period but they also get upgrades, enhancements, new functionalities or new content from the provider during this time. If the buyers pay every time they use the service or product, the seller applies Pay per use (pay-as-you-go) mechanism. 


\subsection{Software pricing}

In software business there are three general revenue models, all including several pricing options. In the first revenue model, software licensing refers to the traditional way to buy the software. In software licensing, customers buy a license that gives right to use the software in a certain amount of computers or processors [17, 18]. In many cases, the length or amount of usage is not limited. In the second revenue model, software renting gives right to use the software for a certain time period that is defined in the rent agreement [5. In the third revenue model, pay-per-use enables software providers to charge customers based on the actual usage of the software [17.

Pricing in these above introduced revenue models may base on different aspects. Lehmann and Buxmann [7] introduced the following pricing parameters:

(i) Price formation: The seller determines the price base (cost-based, value-based or competition oriented) and the degree of interaction between the seller and buyer (unilateral or interactive).

(ii) Structure of payment flow: Payments may be done as single payments, through recurring payments or through a combination of these.

(iii) Assessment base: The number of pricing components, the usage-dependent and usage-independent assessment bases have to be defined.

(iv) Price discrimination: Sellers offer the same good to different buyers at different prices. Price discrimination may be first-degree (prices depend on each user's willingness-to-pay), second-degree (customers may choose one of the offered product-price combinations based on required quantity, software version or time), third-degree (market segmentation by the seller based on personal or regional conditions) or multidimensional (combination of these).

(v) Price bundling: Several items (services, products, rights, etc.) are bound together into an offering with a predetermined price. The offering may be pure bundling (the products are offered exclusively in a bundle), mixed bundling (goods may be bought as a package or separately), unbundling (products may be bought only separately) or customized bundling (customers choose the content of the bundle). In price bundling, software products, maintenance and support services may be packaged together. The degree of integration of the bundle items can be complementary, independent or they can substitute each other. The price level of the bundle can be additive (the price of the bundle is the sum of the prices of the items), superadditive (the price is greater than the sum of individual prices) or subadditive (lower price than the sum of individual prices).

(vi) Dynamic pricing strategies: The seller sets the price dynamically over time. For software products, penetration (setting low prices in the beginning and possibly increasing it later), follow-the-free (the product is free, revenues come from complementary services or extra functionalities) and skimming (high starting prices that may be gradually reduced) pricing strategies are the most important.

Summarizing, the items of SBIFT model [11] and the software pricing parameters [7] overlap each other: some dimensions and parameters refer to the same aspect (Scope-Price bundling, Base-Price determination), some dimensions offer more alternatives than the respective pricing parameter (Influence-Degree of interaction, 
Formula-Assessment base), one of the dimensions takes a different point-of-view than the respective parameter (Temporal rights-Structure of payment flow) and some parameters are missing from the SBIFT model (Price discrimination, Dynamic pricing strategies).

\section{Methodology and data}

In order to evaluate the applicability of the SBIFT model empirically in cloud context and to get an insight into currently used cloud solution pricing models, we studied pricing models of cloud offerings from 54 companies. Our analysis was carried out in September and October 2012 in the following steps: selecting cloud companies for the data sample; search for IaaS-, PaaS- and SaaS-offerings and their pricing information from their webpage; exclusion of those that provide a different type of service or do not provide enough pricing information; evaluation of SBIFT model iteratively. As a result, after searching for pricing data of offerings from more than 160 cloud providers, we could build up 73 pricing models from 54 firms by using the SBIFT model (see Table 1 for more details).

\begin{tabular}{|l|l|l|l|l|}
\hline & IaaS & PaaS & SaaS & Total \\
\hline Number of companies & 7 & 14 & 33 & 54 \\
\hline Number of offerings & 19 & 16 & 33 & 68 \\
\hline Number of pricing models & 20 & 19 & 34 & 73 \\
\hline
\end{tabular}

Table 1. Analyzed pricing models

Data sample selection: To ease the search of the cloud offerings, we identified our sample with the help of an internet portal Cloud Computing Showplace ${ }^{1}$ that enlists more than 2050 cloud companies. In this online directory, cloud provider companies can register and categorize themselves into IaaS, PaaS and SaaS providers. SaaS providers can also categorize themselves by industry sector and application category.

We utilized this portal since it contains the most comprehensive collection of cloud providers compared to other portals (e.g. cloudservicemarket.info or www.saasdir.com) and the number of registered companies are growing continuously, fact that suggests that the directory is an up-to-date, maintained and used portal. To increase the reliability of our sample, we added additional validation steps into the process e.g. by excluding the non-cloud offerings.

We identified our data sample by choosing all registered IaaS and PaaS providers and one SaaS company with relevant pricing data from each industry sector. Since the number of registered SaaS companies is too large and growing constantly, we selected SaaS companies from each industry sector randomly until we had detailed pricing data of at least one SaaS offering from each industry sector in order to increase the industry coverage of the sample data.

\footnotetext{
1 http://cloudshowplace.com
} 
Review of the offerings and disclosure of pricing information: In order to increase the reliability of our data sample method, we reviewed the offerings and excluded the non-IaaS, non-PaaS and non-SaaS services, respectively. Concerning the disclosure of pricing information, our experience is in line with Lehmann et al. 20, who conducted an empirical study on the pricing models of SaaS providers registered on this portal. They found, that especially small and medium size firms provide pricing information on their website. Since not every aspect of the pricing model could be found in most cases, we agreed on excluding data from our sample where the companies did not provide enough information to understand the pricing logic as a whole.

Analysis of the SBIFT model: During our analysis, we matched each pricing model with a SBIFT pricing model pattern that can be defined as a combination of the positions of the pricing model characteristics along the SBIFT dimensions. While defining the positions, we selected the item that described the pricing characteristic in the most accurate way. The evaluation was done in an iterative process with the following evaluation criteria: (i) Each of the characteristics of the pricing model can be matched to a position of a dimension in the SBIFT model. (ii) One pricing pattern in the SBIFT model describes pricing models, that share the same characteristics. If the evaluation criteria was not met, we modified the SBIFT model to address the problems occurred and started a new iteration until the SBIFT model pattern could be defined for each sample data and the evaluation criteria was met.

\section{Research findings}

\subsection{SBIFT model in cloud context}

Based on our study, we propose some modifications to the SBIFT model that is specific to the cloud services industry (see Figure 2). The framework consists of 7 dimensions depicted in continuous scale, that describe the details of the offering. Next the proposed modifications are described compared to the SBIFT model.

Scope dimension: Our study revealed that identifying the level of bundling in the Scope dimension is challenging without some kind of categorization between the cases Attribute and Package. Based on the literature, we identify the categories Package as Pure bundling and Attribute as Unbundling. The combination of these is referred in the literature to as Customized bundling, where customers can choose the components of the bundle while the seller determines the price and scope of the bundle [21]. In IT industry, we see examples of customized bundling when even the price and the scope of the bundle is negotiable. To ease the process of determining the scope level, we propose the categories [Bundling where the amount of some items can be chosen from predefined options] and [Bundling where the amount of some items can be chosen freely].

Tiered pricing: We propose to add a new item to the Formula dimension for offerings with a fixed price and a limitation on the volume or the functionality, where the user has to switch to a less-limited offering with a different price if (s)he requests more volume or functionality. Named as Tiered-pricing, the formula attempts 


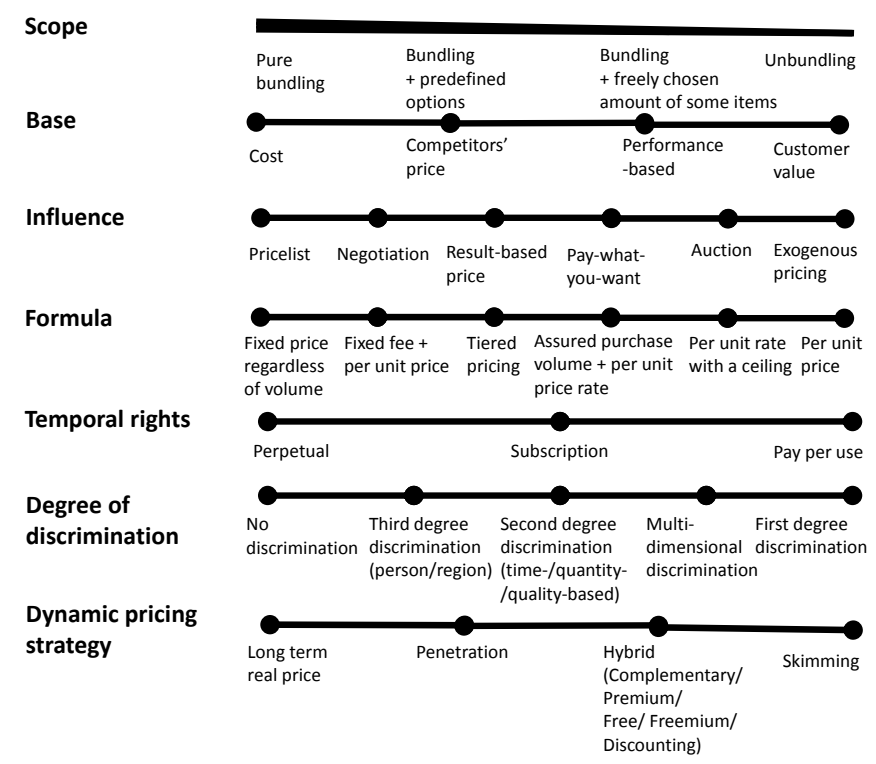

Fig. 2. Cloud Solution Pricing Framework

to package services and products by matching price levels to user's willingness-to-pay 14. This formula is popular among IT offerings that apply vertical versioning.

Subscription-based pricing models: In the Temporal rights dimension of SBIFT model the authors distinguish between Leasing, Renting and Subscription. However, these three concepts are faded in cloud literature (see e.g. [17, [5]), therefore we propose to use the term Subscription meaning Renting and Leasing as well and leaving Renting and Leasing out of the framework as separate items.

Usage-based pricing models: In cloud literature, the term Pay per use pricing is used when the customer is charged on the actual usage, that has to be monitored and measured 22. The customer does not have to make any commitment to use the service or product for a predefined period: there is no obligatory monthly fee, the user pays for the used volume. In digital content pricing literature, units represent a pricing metric that can be either linked to the actual usage or volume of the service/product (usage-dependent metric) or represent only the usage potential (usage-independent metric) [7, 20. Hence, the term usage-based pricing known from cloud industry refers to a SBIFT price model, where the Formula dimension is Per unit price with a usagebased metric and the Temporal rights is Pay per use.

Performance-based pricing: Being a broadly used pricing strategy in integrated solution pricing, we propose to add the category Performance-based pricing to the Base dimension, that takes into consideration both the suppliers' costs and the customers' perceived value. In this case, the seller guarantees a certain performance level for a negotiated price and pays a penalty if this is not achieved [15, 23. 
Proposed dimension: Degree of discrimination: Based on literature review and the wide use of this pricing aspect of our data sample, we propose to add the dimension Degree of discrimination to the SBIFT model. Price discrimination is used when the same product/service is offered for different buyers for different price. This strategy is extremely important for providers of digital goods, since the low marginal costs allow them to sell the offering also for customers with low willingness to pay 7]. The categories of the dimension are proposed as follows.

The left most item is No discrimination, meaning that the product/service is offered for the same price for everybody. In case of First degree discrimination the vendor offers the same product/service with different prices for different customers. Second degree price discrimination is used when providers sell different units of output for different prices [24]. In this case, customers use self-selection to choose from the offers [25. Second degree price differentiations can be quantity-, time- and quality-based [7]. In case of Quantity-based price discrimination the price depends on the amount of the bought goods [24]. When prices differ in different points of times, time-based price discrimination is used. In case of Quality-based price discrimination different product/service variants are offered with different price [26]. When applying Third degree price discrimination, the vendor identifies different customer groups based on their willingness-to-pay [26]. Third degree price discrimination can be Personal (e.g. student discounts) or Regional (e.g. different prices for developing countries) 7]. Multi-dimensional price discrimination occurs when price differentiation is made based on more than one dimension [7].

Proposed dimension: Dynamic Pricing Strategy: Because of its important role in cloud pricing suggested by the literature 7, we propose Dynamic Pricing Strategy to the SBIFT model. Prices set in a dynamic environment can influence the demand behavior of price sensitive customers 27. Dynamic pricing is the strategy where prices are not fixed for a relatively long period, but the seller dynamically changes the prices over time, based on factors such as time of sale, demand information and supply availability. Next the categories of the dimension are proposed.

The first option is the Long-term real price strategy, when prices are kept the same for longer periods and they are adjusted only if necessary, not as a part of a predetermined strategy. The next option is the Penetration strategy, when vendors use low prices for faster market-entry and then increase prices over time [28, 12. In case of Skimming the vendor sets high prices in the early stages of market development and then gradually reduces the prices to attract also more price sensitive market segments [12. Hybrid pricing strategies [14] combine elements of penetration and skimming strategies and may contain for example: Complementary pricing [14, Premium pricing 14, Free [8, Freemium/Follow-the-free [8, 7] or Random or periodic discounting 14].

\subsection{Pricing models in cloud industry}

Our analysis shows, that indeed, currently used pricing models are very complex, difficult to understand and compare (in line with [8, 29]). Solutions appear as a result of co-operation and competition between the actors of the ecosystem, and the interconnectivity between the actors is visible also in the pricing models (in line with [30]). In Figure 3, currently used pricing model characteristics of different service 
sectors are marked, where the values inside the rectangles describe the rounded usage proportions of the respective pricing aspect. In the picture the most popular pricing patterns and the most rarely used categories are also shown. Results related to the dimensions Base and Dynamic pricing strategies are missing from the figure, since there was not enough data regarding these two aspects. It can be seen from the figure, that firms use similar pricing models for IaaS, Paas and SaaS offerings.

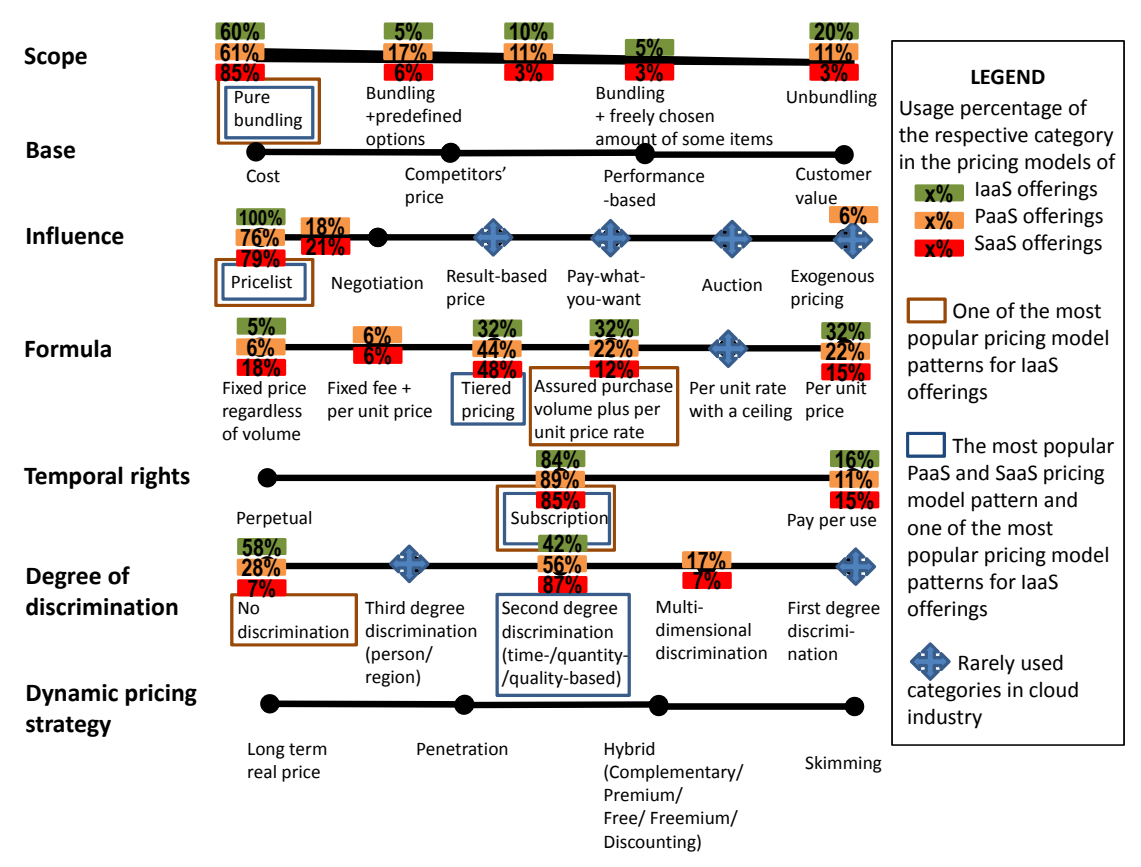

Fig. 3. Currently used pricing models in the cloud industry

\section{Most popular pricing model patterns}

Based on our analysis, we can conclude that cloud providers indeed differentiate by price since there is a big diversity in applied pricing models. The most popular pricing model is [Pure bundling, Pricelist, Tiered pricing, Subscription and Second degree discrimination] for all IaaS, PaaS and SaaS offerings, being applied in more than $20 \%$ of the cases. Price bundling is an effective pricing strategy if variable costs are near zero, or at least relatively low compared to the customers' willingness to pay. On the other hand, using different price bundling and unbundling solutions result in a nontransparent market because of the difficulties in price comparisons, and that effects negatively both the providers and the customers 29. Pricelists are broadly used in cloud industry, especially when there is a large customer base with similar needs. In case of IaaS offerings, another popular pricing model is revealed since IaaS offerings are priced in $20 \%$ of the cases with the pricing model [Pure 
bundling, Pricelist, Assured purchase volume plus per unit price, Subscription and No discrimination]. As a difference to the price model above, customers get the same product for the same price without any discrimination, and they have the option to buy additional resources with a predefined unit price.

Our study revealed also, that Free trial version is offered to the users in 10\%, 90\%, and $56 \%$ of IaaS, PaaS and SaaS offerings, respectively. Besides this hybrid strategy, we met examples of Tiered marginal discounting, which assures that usage increase is not so painful while usage decrease still brings economic benefits for the customer.

\section{Rarely used categories}

Despite of the big diversity in cloud pricing, there are still rarely used categories that may provide differentiation for firms. Based on our findings, one of the rarely used categories is Result-based pricing. However, this category may be often used among business partners, where the actors of the value chain split the generated revenue. Examples of rarely used Pay-what-you-want pricing are the popular games downloadable from Humble Bundle websit $2^{2}$ 31. Auction pricing is also rarely used, however, a good example from IaaS industry could be Amazon's pricing model regarding the EC2 Spot Instances. On the other hand, Shapiro and Varian [32] state that auctions is usually not a viable option for digital goods where the incremental cost of production is zero. Examples of Exogenous pricing are found -however rarely- in SaaS pricing: solutions are priced partly based on the pricing model of IaaS provider - in this case, neither the SaaS provider nor the customer have an influence on this price component. No examples have been found by the authors for the use of Per unit rate with a ceiling in cloud industry. Our study reveals, that Third degree discrimination is not used alone, but it is preferred to be applied together with Second degree discrimination. In addition, First degree discrimination is rarely used in cloud context, probably because providers have difficulties in acquiring knowledge on each user's willingness-to-pay [7].

\section{Conclusions and further research}

Pricing is a strategic tool in manager's hands, where finding a good price model brings success for the companies. On the other hand, it is a challenging task with long-term consequences, where decision makers have to take into consideration many factors, such as the offering itself, the target market segment with specific customer needs, the competitors' similar offerings, the costs, etc. With the sudden growth of different cloud solutions, also pricing has become increasingly complex resulting in a "constantly changing labyrinth" of pricing 8 . In this research, we attempted to find a systematic way to describe the pricing models in order to help decision makers plan, develop and speak about pricing alternatives. The proposed 7-dimensional model is an extended and customized version of the SBIFT model developed for cloud industry, that takes into consideration both the general knowledge about pricing and the specific cloud characteristics.

\footnotetext{
${ }^{2}$ http://www.humblebundle.com/
} 
In this paper, an empirical study has been carried out in order to identify the currently used pricing models of the cloud solutions. We found, that the pricing models of IaaS, PaaS and SaaS offerings have similar patterns, that leads us not to distinguish between different service categories but rather concentrate on pricing of cloud solutions. In line with Kihal et al. [29] and Cusumano [8], we found out also, that the big diversity in the pricing models makes price comparison difficult.

Our study has some limitations that provide avenues for further research. Besides our analysis of pricing information available online, data has to be gathered and studied from other sources as well, e.g. through cases studies or quantitative research. In further research, dependencies between the dimensions and categories have to be studied also. Because of the the dynamic nature of cloud value networks [33], the interaction between different actors of an ecosystem has an impact also on pricing. Offerings are interconnected and pricing models have to be established in a complex service system with multiple stake-holders $[30$. Further work is needed to analyze how the pricing models of different actors enable or limit each other's pricing models [1].

\section{References}

1. Weinhardt, C., Anandasivam, A., Blau, B., Borissov, N., Meinl, T., Michalk, W., Stößer, J.: Cloud computing-a classification, business models, and research directions. Business \& Information Systems Engineering 1(5) (2009) 391-399

2. Anandasivam, A., Premm, M.: Bid price control and dynamic pricing in clouds. In: Proceedings of the European Conference on Information Systems. (2009) 1-14

3. Piercy, N.F., Cravens, D.W., Lane, N.: Thinking strategically about pricing decisions. Journal of Business Strategy 31(5) (2010) 38-48

4. Gourville, J., Soman, D.: Pricing and the psychology of consumption. Harvard Business Review 80(9) (2002) 90-105

5. Ojala, A.: Software renting in the era of cloud computing. In: Cloud Computing (CLOUD), 2012 IEEE 5th International Conference on, IEEE (2012) 662-669

6. Porter, M.: Competitive strategy: Techniques for analyzing industry and competitors. Competitive strategy: techniques for analyzing industry and competitors (1980)

7. Lehmann, S., Buxmann, P.: Pricing strategies of software vendors. Business \& Information Systems Engineering 1(6) (2009) 452-462

8. Cusumano, M.A.: The changing labyrinth of software pricing. Commun.ACM 50(7) (jul 2007) 19-22

9. Schramm, T., Wright, J., Seng, D., Jones, D.: Six questions every supply chain executive should ask about cloud computing. Accenture Institute for High Performance (2010)

10. Hinterhuber, A.: Towards value-based pricing: An integrative framework for decision making. Industrial Marketing Management 33(8) (2004) 765 - 778

11. Iveroth, E., Westelius, A., Petri, C.J., Olve, N.G., Coster, M., Nilsson, F.: How to differentiate by price: Proposal for a five-dimensional model. European Management Journal (2012)

12. Shipley, D., Jobber, D.: Integrative pricing via the pricing wheel. Industrial Marketing Management 30(3) (2001) $301-314$

13. Danziger, S., Israeli, A., Bekerman, M.: The relative role of strategic assets in determining customer perceptions of hotel room price. International Journal of Hospitality Management 25(1) (2006) 129-145 
14. Harmon, R., Demirkan, H., Hefley, B., Auseklis, N.: Pricing strategies for information technology services: A value-based approach. In: System Sciences, 2009. HICSS '09. 42nd Hawaii International Conference on. (2009) 1-10 ID: 1.

15. Bonnemeier, S., Burianek, F., Reichwald, R.: Revenue models for integrated customer solutions: Concept and organizational implementation. Journal of Revenue \& Pricing Management 9(3) (2010) 228-238

16. Sundararajan, A.: Nonlinear pricing of information goods. Management Science 50(12) (Dec. 2004) pp. 1660-1673

17. Ojala, A.: Revenue models in saas. IT Professional (2012)

18. Ferrante, D.: Software licensing models: What's out there? IT Professional 8(6) (2006) $24-29$

19. Choudhary, V.: Comparison of software quality under perpetual licensing and software as a service. J. Manage. Inf. Syst. 24(2) (October 2007) 141-165

20. Lehmann, S., Draisbach, T., Buxmann, P., Dörsam, P.: Pricing of software as a servicean empirical study in view of the economics of information theory. Software Business (2012) 1-14

21. Hitt, L., Chen, P.: Bundling with customer self-selection: A simple approach to bundling low-marginal-cost goods. Management Science (2005) 1481-1493

22. Armbrust, M., Fox, A., Griffith, R., Joseph, A., Katz, R., Konwinski, A., Lee, G., Patterson, D., Rabkin, A., Stoica, I., et al.: A view of cloud computing. Communications of the ACM 53(4) (2010) 50-58

23. Becker, M., Borrisov, N., Deora, V., Rana, O.F., Neumann, D.: Using k-pricing for penalty calculation in grid market. In: Hawaii International Conference on System Sciences, Proceedings of the 41st Annual. (2008) 97-97 ID: 1.

24. Varian, H.: Differential pricing and efficiency. First Monday 1(2-5) (1996)

25. Spiegel, Y.: Second degree price discrimination. Tel Aviv University (1997)

26. Varian, H.: Versioning information goods. University of California, Berkeley (1997)

27. Anandasivam, A., Buschek, S., Buyya, R.: A heuristic approach for capacity control in clouds. In: Commerce and Enterprise Computing, 2009. CEC'09. IEEE Conference on, Ieee (2009) 90-97

28. Dean, J.: Pricing pioneering products. The Journal of Industrial Economics (1969) 165-179

29. El Kihal, S., Schlereth, C., Skiera, B.: Price comparision for infrastructure-as-a-service

30. Ng, I.C.L.: The future of pricing and revenue models. Journal of Revenue \& Pricing Management 9(3) (2010) 276-281

31. Jurisic, M., Kermek, D.: Taxonomy of digital economy business models. In: MIPRO, 2011 Proceedings of the 34th International Convention, IEEE (2011) 1414-1419

32. Shapiro, C., Varian, H.: Information rules: a strategic guide to the network economy. Harvard Business Press (1998)

33. Ojala, A., Tyrväinen, P.: Value networks in cloud computing. Journal of Business Strategy 32(6) (2011) 40-49 